\title{
OBJECT-ORIENTED APPROACH FOR 3D ARCHAEOLOGICAL DOCUMENTATION
}

\author{
R. Valente ${ }^{\text {a, }}$, R. Brumana ${ }^{\text {a, D. Oreni }}{ }^{\text {a }}$, F. Banfi ${ }^{\text {a }}$, L. Barazzetti ${ }^{\text {a }}$, M. Previtali a
}

a ABC Dept., Politecnico di Milano, Italy - (riccardo.valente, raffaella.brumana, daniela.oreni, fabrizio.banfi, luigi.barazzetti, mattia. previtali)@polimi.it

KEY WORDS: Archaeology; Documentation; Structure from Motion; 3D Modelling; Stratigraphy; Material and Immaterial Evidences; Human Remains.

\begin{abstract}
:
Documentation on archaeological fieldworks needs to be accurate and time-effective. Many features unveiled during excavations can be recorded just once, since the archaeological workflow physically removes most of the stratigraphic elements. Some of them have peculiar characteristics which make them hardly recognizable as objects and prevent a full 3D documentation. The paper presents a suitable feature-based method to carry on archaeological documentation with a three-dimensional approach, tested on the archaeological site of S. Calocero in Albenga (Italy). The method is based on one hand on the use of structure from motion techniques for on-site recording and 3D Modelling to represent the three-dimensional complexity of stratigraphy. The entire documentation workflow is carried out through digital tools, assuring better accuracy and interoperability. Outputs can be used in GIS to perform spatial analysis; moreover, a more effective dissemination of fieldworks results can be assured with the spreading of datasets and other information through web-services.
\end{abstract}

\section{INTRODUCTION}

Documentation phase is crucial in Archaeology, since excavations usually remove most of the discovered features. Traditional recording methods are mainly manual: they allow a direct knowledge of the surveyed object but they are timeconsuming and sometimes lacking geometric accuracy. There are at least two more critical points for what concerns this approach. The first one is that paper-based documentation, i.e. mainly plans and sections, provides $2 \mathrm{D}$ outputs. The $3 \mathrm{D}$ aspect of stratigraphic layers is seldom represented because of: 1- practical constraints in correctly representing their morphology and 2- high richness and complexity of the archaeological features. Due to these reasons, traditional approach to archaeological documentation has rarely included 3D outputs, being basically based on images and drawings. The second one is that data exchange and analysis is usually less feasible with traditional methods. If raw datasets, such as measurements and drawings, are in a non-digital format, they need to be digitalized to take advantages of digital tools like vector drawing or GIS which are already considered firm standards for archaeological documentation (Conolly and Lake, 2006). This fact is also a relevant barrier for a more effective dissemination of contents and results to a larger audience. Any further operation to obtain digital data from paper-based documentation is time-consuming and can introduce errors, lowering the quality.

This paper presents a recording methodology for archaeological fieldworks which is completely based on the use of digital tools and considers the 3D characteristics of some archaeological features. Although 3D techniques are more expensive than traditional methods, the presented workflow is reasonably cost-effective. The method has been widely tested on an archaeological case study. The practical workflow as well as results and considerations are discussed.

\section{CASE STUDY}

Selected case study was the archaeological site of S. Calocero in Albenga. the sites presents large archaeological and architectural remains of a religious settlement (church and monastery) probably founded during the 6th century on a previous funerary area, where presumably the martyr Calocero had been buried, and used and modified until the 16th century (Spadea Noviero et al., 2010). During a two-years campaign (September-October 2014 and 2015) four different trenches (VIb-VIII-IX-X) were opened to be investigated (Pergola et al., 2015). All of them have been documented through the presented methodology but most of tests have been performed on trench VIb, located in front of the church façade (Fig. 1). Excavations unveiled a rich stratigraphy and burials useful to experiment the potentialities of this documentation method.

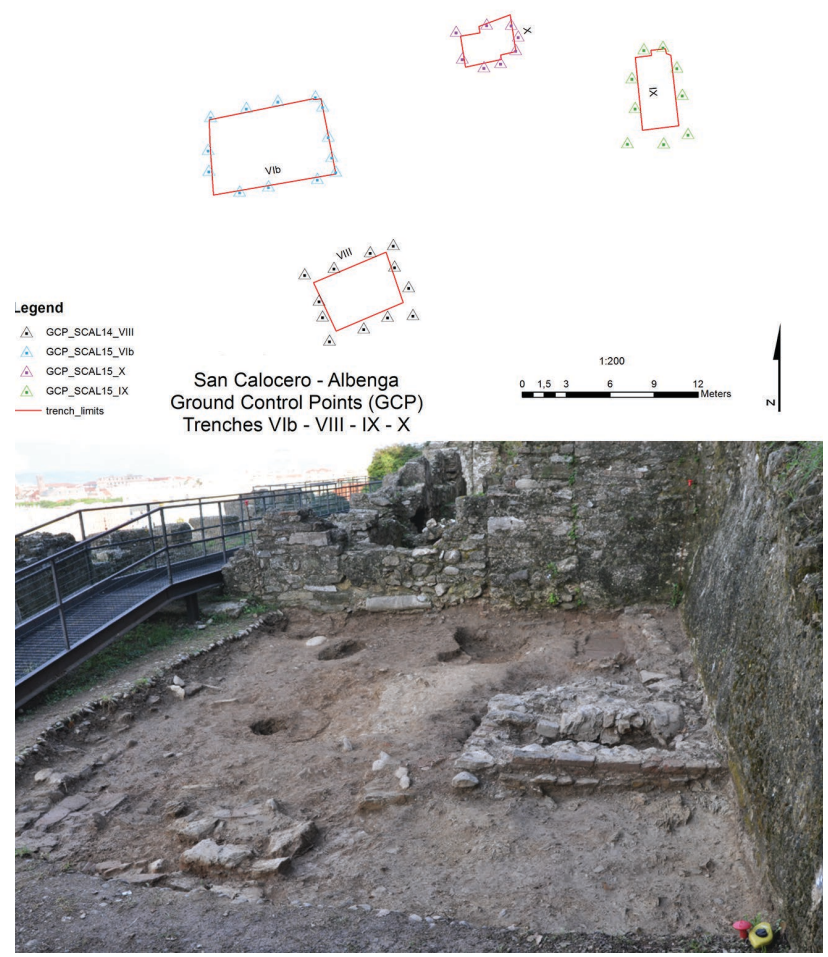

Figure 1. Trench positioning (above) and detail of trench VIb (below).

* Corresponding author 


\section{EVIDENCE IDENTIFICATION}

\section{1}

\section{Main Characteristics of Archaeological Features}

Prior to set up the practical workflow, a complete identification of the nature and characteristics of evidence to be modelled was required. The main features to be considered have been identified in findings, structures and elements of soil stratigraphy, i.e. deposits and interfaces. The main focus has been dedicated to deposits and interfaces, with a further focus on human remains, which can be considered as a particular category of findings. Human remains are preserved after the excavation but as single bones, so they lose their unity once picked up and survive as if they were normal findings.

Stratigraphic elements are more complex to be described. Deposits are layers made out of soil or other material (e.g. debris) which usually covers other features and contain findings; they are tangible elements but they can be mainly perceived from above (or occasionally from aside, e.g. in sections). Moreover, due to their physical characteristics they cannot be moved or handled as objects, and the only way to recognize them is to be partially or integrally excavated. From an archaeological point of view, the upper surfaces of deposits, called horizontal layer interfaces, are crucial, because most of the past actions occurred upon them and because help archaeologists to correctly identify the deposit morphology: for these reasons they are sometimes considered as single-surface entities (Carandini, 2010, p. 69; Harris, 1989, pp. 54-55). Some of their main characteristics can be resumed in: irregular morphology, with a physical behaviour comparable to fluids; being not perceivable in their entirety; not movable; not clearly defined by boundaries, at least before their partial removal.

Feature interfaces are another fundamental element to be considered (Harris, 1989, pp. 59-60). They are completely immaterial and indicate an action of removal or subtraction of material ("cuts"), and can be imagined as surfaces in themselves (Harris, 1989, pp. 59-64). They do not exist in any tangible form, but they are conceived by archaeologists to correctly understand the stratigraphic sequence.

\subsection{Digital Modelling Requirements}

As previously presented, some of the most common archaeological evidence detected during fieldworks cannot be considered as real objects. Objects need some fundamental requirements, such as, among the others, having third dimension, being composed of matter, being bounded by surfaces, being existent in public space, being perdurable through time, being manipulable and having qualitative complexity. (Joske, 1967; Stroll, 1988). It is evident that both archaeological deposits and interfaces do not own all of these properties. Feature interfaces are completely immaterial, even if they can be represented as the surface of the volume of matter removed from its material counterparts. Human remains, although their materiality, share with deposits the impossibility of being manipulated in their unity. All of these aspects are a further constraint to a full 3D approach applied to archaeological stratigraphy. Furthermore, it is quite difficult to collect enough data to obtain a satisfying reproduction of deposits and interfaces morphology with traditional methods.

In order to overcome some of these limits, a different approach was necessary. Deposits have been modelled as three dimensional digital objects having a central body bounded by upper and lower surfaces. Since upper surfaces are the only ones detectable during the fieldworks, they have been used as lower surfaces, i.e. as boundaries, for deposits which cover them. This procedure overcomes the issue caused by the impossibility to observe deposit shape in just one time.

Feature interfaces have been represented as surfaces and their morphology has been taken from the positive counterpart recorded in deposits. A typical example of feature interface is a posthole cut in a larger deposit with its filling. In this case two surfaces have been required: the first one recording the larger deposit and the filling, the second one recording the empty posthole. The surface of deposit where the posthole was cut has been used to generate also the feature interface and the lower boundaries of the filling (Fig. 2). Applying this approach for every stratigraphic units (SU) allows to obtain an effective threedimensional reproduction of the archaeological stratigraphy.

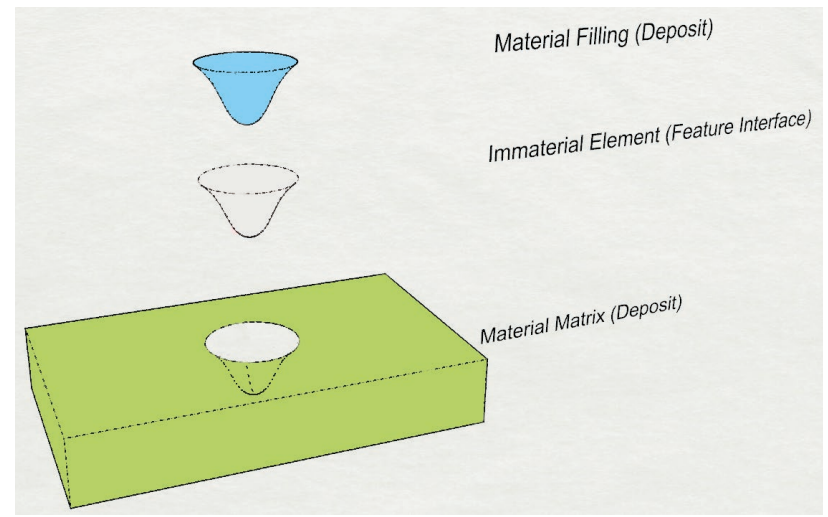

Figure 2. Morphology of material deposits allows to model also feature interfaces and related fillings.

\section{PRESENTED METHODOLOGY}

The presented methodology uses digital photogrammetry supported by topographic and GPS measurements to collect

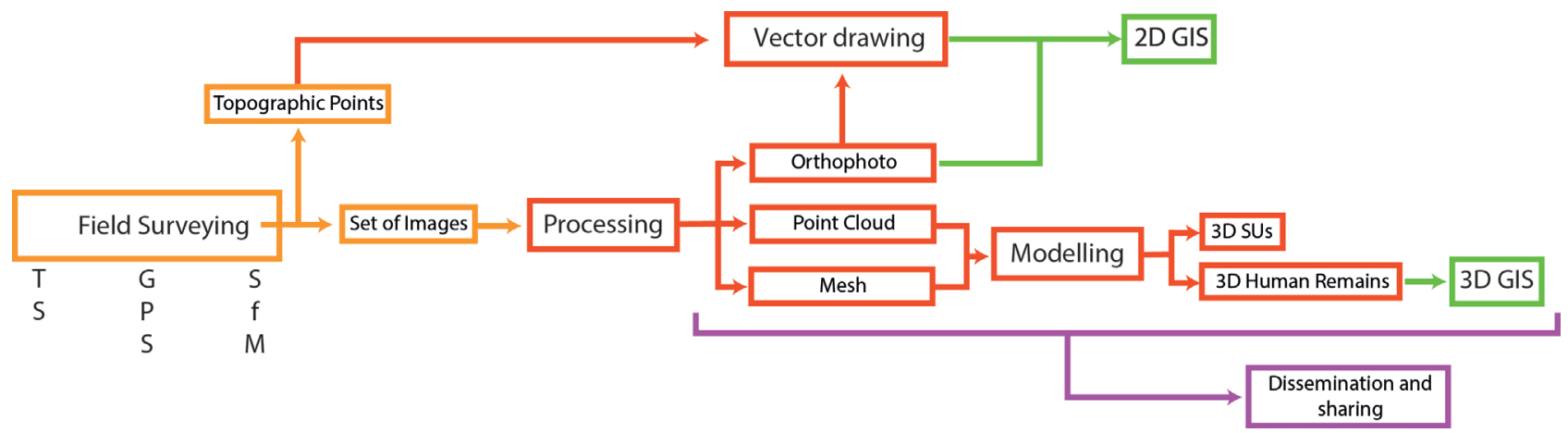

Figure 3: overall workflow of the presented methodology. 
the main datasets during the fieldworks. Raw datasets are successively used to get 2D and 3D outputs (Fig. 3). Orthophotos are used together with topographic points to obtain vector drawings which can be uploaded, together with the previous elements, in GIS environment. Point clouds and meshes allow to obtain 3D outputs through the use of digital modelling. All the digital outputs can be further shared and disseminated in different formats. Details about the methodology are presented in the following paragraphs.

\subsection{On-field Methodology}

On-field recording has been based on one hand on GPS and total station (TS) to measure topographic points and on the other hand on the use of photogrammetric techniques. GPS points have been used to georeference the trenches, while TS measurements have been used to record the boundaries of single (SUs). Photogrammetric projects have been processed with Agisoft PhotoScan $^{\odot}$ Pro; the use of digital photogrammetry has been already tested for the recording of archaeological fieldworks in progress, showing the potentialities of the method (De Reu et al., 2014, 2013; Plets et al., 2012; Stal et al., 2014). It allows us to obtain accurate digital models of the unveiled archaeological surfaces and to extract orthophotos which are extremely effective to record the SUs, integrating traditional images. The entire workflow has been designed as follows: a series of ground control points (GCPs; $3.7 \mathrm{~mm} \times 3.7 \mathrm{~mm}$ checkboard targets and 12-bit coded markers) has been set around the archaeological trenches in order to provide the correct georeferencing of models and orthophotos; largest trench covered an area of about 40 sqm. Thirteen GCPs have been positioned outside trench VIb, in order to be set and measured just once per campaign. After the identification of each SU, the boundaries have been measured by TS and a dedicated photogrammetric project has been set before the traditional shootings. Since TS measurements and traditional images are already part of the normal archaeological surveying, the only addition has been the photogrammetric set. Images have been taken with an uncalibrated camera (Nikon D90, 12.3 megapixel equipped with a Sigma lens 20mm F1.8 EX DG ASP $\mathrm{RF}$ ); The camera has not been calibrated since past comparisons between not calibrated cameras and more accurate instruments demonstrated that accuracy needed for this kind of applications is still preserved (Barazzetti and Scaioni, 2014; Chandler et al., 2005; Green et al., 2014; James and Robson, 2012; Sapirstein, 2016; Wackrow et al., 2007). Photogrammetric blocks have been set both for every single SUs and open areas; needed images were included into a range of 15 and 70 . The image acquisition phase took ten minutes maximum, a time observed also in other scientific experiences (Bianchini et al., 2015). In particular occasions, such as during grave excavations, more photogrammetric projects have been set for the same SU in different times, in order to assure a better documentation of the ongoing fieldworks. Images have been processed and georeferenced during the campaigns, in order to keep the pace of excavation progresses. Root mean square deviation over fifty photogrammetric projects realized in 2015 showed a value of $\pm 4 \mathrm{~mm}$, which is a good value to assess accuracy; a ground sample distance of $1 \mathrm{~mm}$ as been set for orthophotos. During 2014 campaign, an overall number of 43 orthophotos has been generated, 73 in 2015.

\subsection{Post-fieldwork activities}

\subsubsection{D Outputs}

Topographic points and orthophotos have been used to realize vector drawings of discovered SUs. The combined use of TS measurements and orthoimages assured high accuracy and correspondence between different drawings, in order to improve the accuracy of traditional plans and sections realized during fieldworks (Fig. 4). Vector drawing can be equally managed in software like AutoCAD ${ }^{\circ}$ or GIS, being both points and orthophotos georeferenced. Points helped in individuating the features where not clearly visible on images, a very common issue especially for what concerns deposits. 2D outputs are important also because are explicitly required by the Italian regulations about archaeological fieldworks.

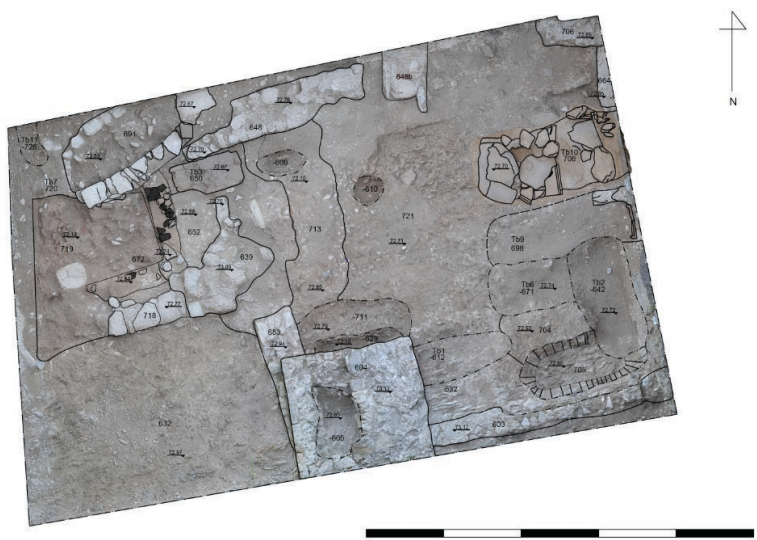

Figure 4. Vector drawing (plan) on orthoimage of SUs in trench $\mathrm{VIb}$, in front of church façade (scalebar $=5 \mathrm{~m}$ ).

\subsubsection{Deposits and Interface Modelling}

Since one of the aim was trying to reach a surveying approach focused on 3D objects, a possible digital modelling of archaeological evidence has been planned using collected field data. Three-dimensional representation of archaeological stratigraphy is a long-standing topic connected to digital surveying (Alvey, 1993). Many solutions have been proposed to record the third dimension of deposits, such as the creation of a triangulated irregular network (TIN) from a TS point grid (D'Andrea and Barbarino, 2012; Putzolu et al., 2002); the use of meshes coming from laser scanner surveys (De Felice et al., 2008), from laser scanner and photogrammetric surveys (Berggren et al., 2015; Forte, 2014), or only from digital photogrammetry (Poggi, 2016; Roosevelt et al., 2015). In this case, a different approach has been tested.

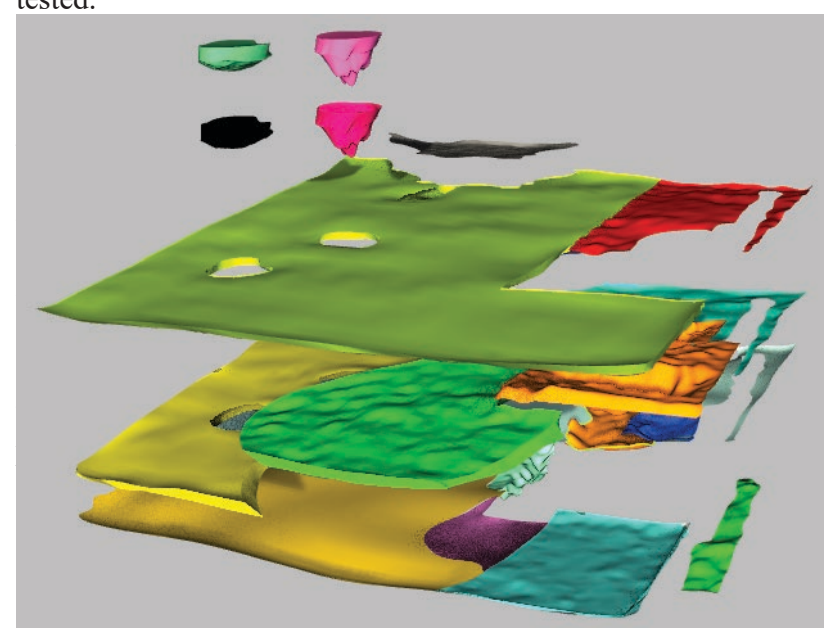

Figure 5. A sample of three-dimensional stratigraphic sequence in trench VIb, exploded view (cfr. Fig. 3). 
All generated digital surfaces obviously corresponded to upper archaeological surfaces of deposits. Different upper surfaces have been joined together through a series of manual operations and a constant comparison with stratigraphic data in order to represent thickness of deposits, making them visible in their whole unity (Fig. 5).

Although many studies refer to digital photogrammetry as a method for 3D registration of archaeological features, it is worth to underline that three-dimensional output is a digital surface, while the volume of the feature is not recorded (Fig. 6).

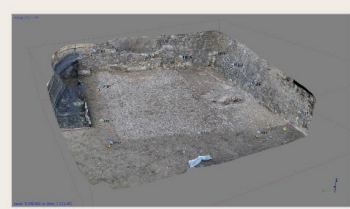

Photogrammetric surface reconstruction

\section{$\neq$}

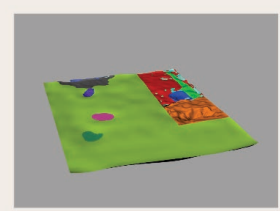

3D Modelling
Figure 6. Photogrammetric 3D reconstruction is limited to surfaces, unlike digital modelling.

As previously described, it is basically impossible to have an effective three-dimensional recording of archaeological deposits on the field, due to their physical characteristics. Nevertheless, the photogrammetric approach finds some unexpected correspondences with archaeological methodology, since both are focused on surfaces; there is a continuous connection among surfaces from a cognitive, surveying and archaeological point of view. The method allowed also to represent feature interfaces as three-dimensional surfaces, integrating the digital stratigraphy in a more effective way.

\subsubsection{Human remains Modelling}

A similar approach has been applied also to human remains, some of the most frequent evidence unveiled during archaeological excavations. Also in this case, one of the main issues was the

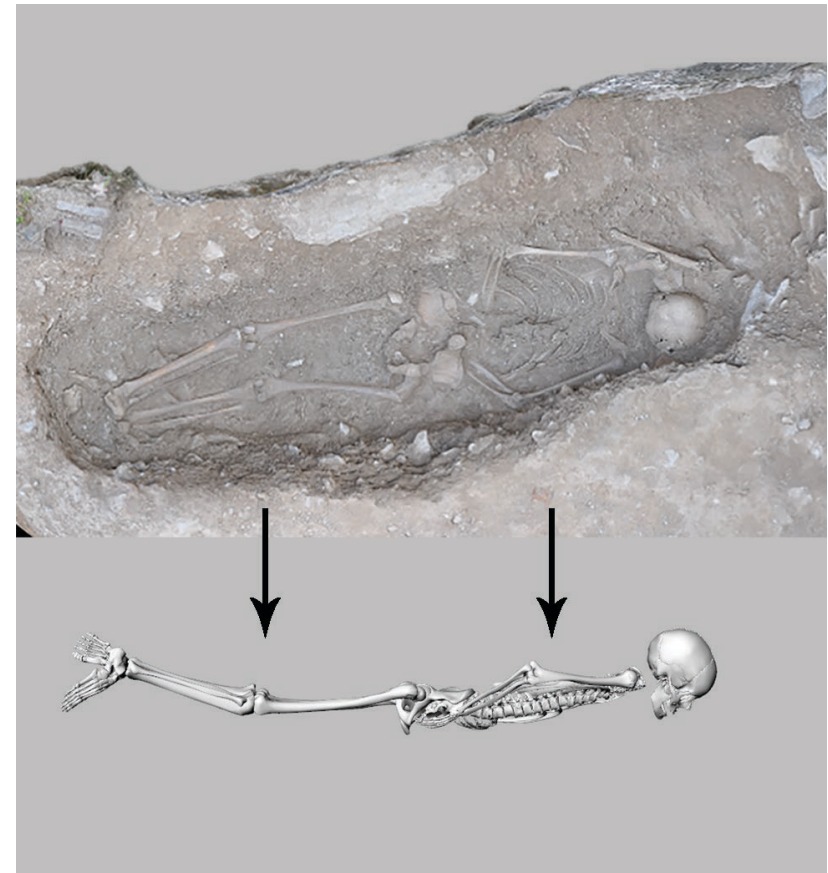

Figure 7. Buried individual from trench VIb represented in three dimensions. possibility to picture the buried individuals only from above. The photogrammetric surface was able to reconstruct in a satisfying way only the upper appearance of graves, either unexcavated or without the relative filling, but was basically unable to provide other information about the precise location of bones.

The combined use of photogrammetric meshes and digital bones allowed to propose a three-dimensional reconstruction of the burial, reaching a different level of representation for archaeoanthropological purposes (Fig. 7). Tests have been encouraging, helping archaeologists and anthropologists in better understanding the nature of funerary contexts also during postexcavation activities.

\subsubsection{Further Use of Data and Dissemination of Results}

Working with digital data, use and dissemination are improved. Topographic points, orthoimages and vector drawings can be successfully imported in GIS, where part of the archaeological documentation can be managed and additional spatial analysis can be performed.

Three-dimensional representations of stratigraphic sequence can be also exported in a 3D GIS environment, as well as 3D human remains: exporting and importing have been tested in ArcScene $\mathbb{C}$ software. It is worth to notice that, although modelled in different phases, different digital objects can be displayed in the same digital environment being within the same reference system (Fig. 8 ). Once in GIS, attributes and data can be added to single entities.

Digital models can be also used to create contents useful for disseminations, and easily shared on the web. For instance, some photogrammetric meshes have been uploaded on an academic account on the popular website SketchFab (https://sketchfab. com/GIcarus.Lab) used to share digital models; the site allows also to add some information directly on the models, improving the interactivity with the user. Some contents (raster and vector datasets) could be also spread through Web Map Services or Web Feature Services, as defined by the Open Geospatial Consortium (http://www.opengeospatial.org/).

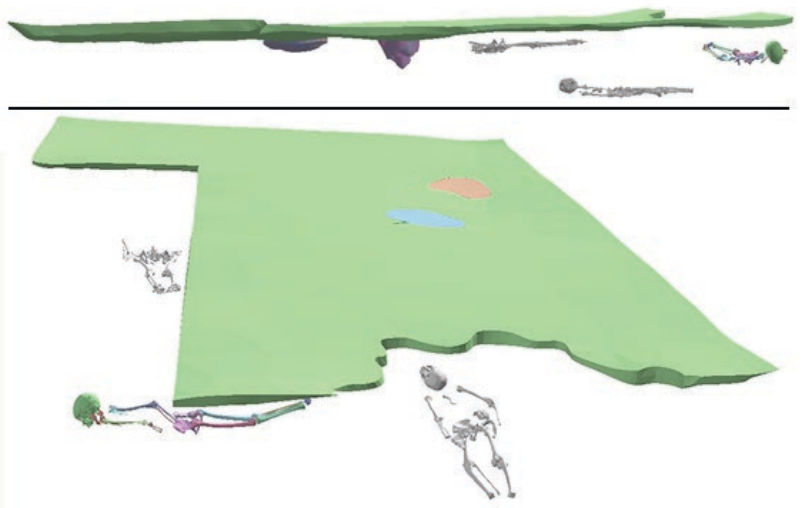

Figure 8. Modelled SUs and human remains in GIS (ArcScene).

\section{CONCLUSIONS}

The paper presented a feasible methodology to overcome 2D documentation to record progresses during archaeological fieldworks and going towards an object-oriented approach for archaeological modelling. Effectiveness of digital photogrammetry for documenting archaeological fieldworks has been confirmed: it can be integrated with the usual documentation activities performed on fieldworks and can provide numerous raw outputs which can be successively used. Even if it does not allow 
to re-enact the entire excavation, results can be an important support for research, also for future reanalysis of data.

In addition to a relevant increasing of accuracy for what concerns traditional two-dimensional outputs, the method allows to introduce a 3D object-oriented approach into archaeological documentation. Digital modelling of deposits and interfaces can be realized using only collected data, without any other operation needed on the field. Different archaeological surfaces can be joined together and edited to obtain the volume and morphology of deposits; both material deposits and immaterial feature interfaces can be represented and integrated, displaying the entire stratigraphic sequence and human remains in three dimensions. Results can be used to complete the standard documentation, to be used in GIS software or disseminated on the web. The representation of deposits and interfaces as digital objects is able on one hand to partially restore the unity of the site, because while structures are often preserved in situ and findings are stored in museums or deposits, soil stratigraphy is normally removed, on the other hand can make them perceivable as if they were objects, an aspect which is not possible to reach directly during excavations. Three-dimensional representations of burials proved to be a feasible solution for archaeoanthropological purposes. It has to be noticed that while the on-field phase is fast and relatively easy, post-excavation activities can be challenging and time-consuming. The modelling of archaeological stratigraphy can be hard to perform in case of excavations with a very complex stratigraphy, when deposits have a thickness of only few centimetres or in case of an excavation with hundreds of SUs. NURBS surfaces are generally less demanding than meshes for what concerns size, but very large fieldworks could result difficult to be managed. In these cases, there could be issues in modelling and displaying deposits and interfaces in a proper way, with possible topological inconsistencies among different SUs.

\section{ACKNOWLEDGEMENTS}

The authors want to thank: prof. Philippe Pergola, who had the scientific direction of the archaeological fieldworks in Albenga, and dott. Stefano Roascio and dott.ssa Elena Dellù, who managed the on-field operations; dott. Giovanni Svevo for the help with on-field survey. Thanks to Fondazione Lamboglia and Fondazione De Mari which funded fieldworks.

A special thanks to Fondazione Fratelli Confalonieri which funded the research.

\section{REFERENCES}

Alvey, B.A.P., 1993. Interpreting Archaeology with Hindsight: the use of three dimensions in graphic recording and site analysis, in: Harris, E.C., Brown III, M.R., Brown, G.J. (Eds.), Practices of Archaeological Stratigraphy. Academic Press, London, pp. 218-228.

Barazzetti, L., Scaioni, M., 2014. Reality-Based 3D Modelling from Images and Laser Scans: Combining Accuracy and Automation, in: Cipolla-Ficarra, F.V. (Ed.), Advanced Research and Trends in New Technologies, Software, Human-Computer Interaction, and Communicability. IGI Global, pp. 294-306. doi:10.4018/978-1-4666-4490-8

Berggren, Å., Dell'Unto, N., Forte, M., Haddow, S., Hodder, I., Issavi, J., Lercari, N., Mazzucato, C., Mickel, A., Taylor, J.S., 2015. Revisiting reflexive archaeology at Çatalhöyük: integrating digital and 3D technologies at the trowel's edge. Antiquity, 89, 433-448. doi:10.15184/aqy.2014.43
Bianchini, C., Borgogni, F., Ippolito, A., 2015. Advantages and disadvantages of digital approach in archaeological fieldwork, in: Giligny, F., Djindjian, F., Costa, L., Moscati, P., Robert, S. (Eds.), CAA2014. 21st Century Archaeology. Concepts, Methods and Tools. Proceedings of the 42nd Annual Conference on Computer Applications and Quantitative Methods in Archaeology. pp. 95105.

Carandini, A., 2010. Storie dalla terra: Manuale di scavo archeologico. Torino.

Chandler, J.H., Fryer, J.G., Jack, A., 2005. Metric capabilities of low-cost digital cameras for close range surface measurement. Photogrammetric Record, 20, 12-26. doi:10.1111/j.14779730.2005.00302.x

Conolly, J., Lake, M., 2006. Geographical Information Systems in Archaeology. Cambridge.

D’Andrea, A., Barbarino, M., 2012. Modellare lo scavo archeologico: esperienze e tecniche a confronto. Archeologia e Calcolatori, 23, 229-245.

De Felice, G., Sibilano, M.G., Volpe, G., 2008. Ripensare la documentazione archeologica: nuovi percorsi per la ricerca e la comunicazione TT - Rethinking the archaeological record: new paths for research and communication. Archeologia e calcolatori , 19, 271-291.

De Reu, J., De Smedt, P., Herremans, D., Van Meirvenne, M., Laloo, P., De Clercq, W., 2014. On introducing an image-based $3 \mathrm{D}$ reconstruction method in archaeological excavation practice. Journal of Archaeological Science, 41, 251-262. doi:10.1016/j. jas.2013.08.020

De Reu, J., Plets, G., Verhoeven, G., De Smedt, P., Bats, M., Cherretté, B., De Maeyer, W., Deconynck, J., Herremans, D., Laloo, P., Van Meirvenne, M., De Clercq, W., 2013. Towards a three-dimensional cost-effective registration of the archaeological heritage. Journal of Archaeological Science, 40, 1108-1121. doi:10.1016/j.jas.2012.08.040

Forte, M., 2014. 3D Archaeology: New Perspectives and Challenges - The Example of Çatalhöyük. Journal of Eastern Mediterranean Archaeology and Heritage Studies, 2, 1-29. doi:10.1353/ema.2014.0004

Green, S., Bevan, A., Shapland, M., 2014. A comparative assessment of structure from motion methods for archaeological research. Journal of Archaeological Science, 46, 173-181. doi:10.1016/j.jas.2014.02.030

Harris, E., 1989. Principles of archaeological stratigraphy. London. doi:10.1007/s007690000247

James, M.R., Robson, S., 2012. Straightforward reconstruction of 3D surfaces and topography with a camera: Accuracy and geoscience application. Journal of Geophysical Research: Earth Surface, 117. doi:10.1029/2011JF002289

Joske, W.D., 1967. Material objects. New York.

Pergola, P., Roascio, S., Spadea, G., Dellù, E.R., Castiglia, G., Svevo, G., Valente, R., 2015. Il complesso di San Calocero 
ad Albenga alla luce dei nuovi dati (campagna di scavo in concessione al Pontificio Istituto di Archeologia Cristiana del 2014). Rivista Di Archeologia Cristiana, 90, 323-379.

Piegl, L., Tiller, W., 1997. The NURBS book.

Plets, G., Gheyle, W., Verhoeven, G., De Reu, J., Bourgeois, J., Verhegge, J., Stichelbaut, B., 2012. Three-dimensional recording of archaeological remains in the Altai Mountains. Antiquity, 86, 884-897.

Poggi, G., 2016. Documentation and Analysis Workflow for the On-going Archaeological Excavation with Image-Based 3d Modelling Technique: the Case-study of the Medieval Site of Monteleo, Italy, in: Campana, S., Scopigno, R., Carpentiero, G., Cirillo, M. (Eds.), CAA2015. Keep the Revolution Going. Proceedings of the 43rd Annual Conference on Computer Applications and Quantitative Methods in Archaeology. pp. 369-376.

Putzolu, C., Laurenza, S., Carafa, P., 2002. Stratigraphic excavation from the field to the computer: the Pompeii prototype, in: Nicolucci, F. (Ed.), Virtual Archaeology: Proceedings of the VAST Euroconference, Arezzo 24-25 November 2000. pp. 115122.

Roosevelt, C.H., Cobb, P., Moss, E., Olson, B.R., Ünlüsoy, S., 2015. Excavation is Destruction Digitization: Advances in Archaeological Practice. Journal of Field Archaeology, 40, 325346. doi:10.1179/2042458215Y.0000000004

Sapirstein, P., 2016. Accurate measurement with photogrammetry at large sites. Journal of Archaeological Science, 66, 137-145. doi:10.1016/j.jas.2016.01.002

Spadea Noviero, G., Pergola, P., Roascio, S. (Eds.), 2010. Albenga. Un antico spazio cristiano. Chiesa e monastero di San Calocero al Monte. Un complesso archeologico dal I dC al XVI secolo. Genova.

Stal, C., Van Liefferinge, K., De Reu, J., Docter, R., Dierkens, G., De Maeyer, P., Mortier, S., Nuttens, T., Pieters, T., van den Eijnde, F., van de Put, W., De Wulf, A., 2014. Integrating geomatics in archaeological research at the site of Thorikos (Greece). Journal of Archaeological Science, 45, 112-125. doi:10.1016/j.jas.2014.02.018

Stroll, A. (1988). Surfaces. Minneapolis.

Wackrow, R., Chandler, J.H., Bryan, P., 2007. Geometric consistency and stability of consumer-grade digital cameras for accurate spatial measurement. The Photogrammetric Record, 22, 121-134. doi:10.1111/j.1477-9730.2007.00436.x 